\title{
A history of sexually transmitted diseases in Thailand: policy and politics
}

\author{
S D Bamber, K J Hewison, P J Underwood
}

\begin{abstract}
This paper provides a brief history of sexually transmitted diseases (STDs) in Thailand. The presentation is divided into three main sections: the period up to the 1930s; the period from the 1930 s until the end of the early 1980s; and the period from the early 1980 s until the present, the so-called 'AIDS Era'. The discussion in each of these sections focuses, as far as sources permit, on the epidemiological picture, as well as describing public and official responses to these diseases. In the final part of the paper consideration is given to these findings in relation to the present situation in Thailand regarding the HIVIAIDS epidemic.
\end{abstract}

(Genitourin Med 1993;69:148-157)

\section{Introduction}

In the wake of the extensive publicity recently given to the HIV/AIDS epidemic in Thailand has come a renewed interest in an old topic, that of sexually transmitted diseases (STDs). Thailand has often been the focus of international attention regarding the sex industry in its relation especially to the stationing of foreign troops in Thailand in the 1960s and 1970 s and, more recently, to international tourism

However, this is a superficial view of the situation regarding STDs in Thailand which does little justice to the topic. It ignores the complex nature of the relationship between STDs and some of the social, economic and political forces operating in the country. These include the position of women, the important social and economic role of the sex industry, in regard to both the domestic and international markets, the question of Thai identity, and the position of minority groups, in particular those in border regions. The extent to which these forces can influence the occurrence of disease has been illustrated graphically by the HIV/AIDS problem.

University of Western Australia and Murdoch University $S$ D Bamber K J Hewison

P J Underwood

Address for correspondence: Dr M Lewis, Dept of Public Health, A27 University of Sydney, NSW 2006 Australia.

Accepted for publication 4 December 1992
However, while the HIV/AIDS epidemic has served to reveal the importance of these issues, it is clear that they are not simply a recent phenomenon; indeed an examination of the history of STDs in Thailand may be of considerable help in understanding the present situation.

In this paper, then, an attempt is made to place the topic of STDs in Thailand in historical perspective. The paper is divided into three broad periods: the first covers the premodern period of Thai history, up until the 1930 s; the second from the 1930s until the early 1980 s, prior to the entry of AIDS onto the scene; and the third section looks at the period from the early 1980s until the present day, the AIDS era.

Given the constraints of the present article, this examination cannot hope to be exhaustive. We have therefore tried to concentrate the presentation on the three lodestars of classic epidemiology: time, or when infection or symptoms appear; place, or where the infected persons are found; and person, or the characteristics of who is infected. From such a description we hope to flesh out not only how STDs spread, but why they spread as fast as they did, as well as to follow the responses of Thai society to the burgeoning epidemic.

\section{STDs in the period prior to the 1930s}

STDs were clearly prevalent among Thais in the pre-modern era. The earliest available account comes from a European, the French envoy La Loubère, who visited Ayuthaya, then the seat of royalty, in 1687 , and referred to the frequency of "the ill consequences of a debauch", adding that 'they know not whether they [such diseases] are ancient or modern in their Country". "The first known reference in Thai sources comes in one of the 18th century Ayuthayan chronicles where it is recorded that in 1755 a court noble fell ill with "men's disease" (rok samrap burut). ${ }^{2}$

Descriptions of diseases with symptoms consistent with those of STDs are also to be found in the medical inscriptions erected at Wat Phrachetuphon (Wat Pho) during the Third Reign (King Nangklao, 1824-1851) and in the collection of traditional Thai medical texts compiled during the Fourth Reign (King Mongkut, 1851-1868). ${ }^{4}$ The close resemblance between these two descriptions indicates a common source. It is notable that even in these early texts an association is made between prostitution and STDs. This association is a common factor throughout the period under discussion in this paper, hence any discussion of STDs is also a discussion of the regulation of prostitution.

\section{Prevalence}

Until very recent times there is very little information on the prevalence of STDs among the Thai population. The earliest references consist of anecdotal evidence and the records kept by Western medical missionaries 
such as the American missionary, Dr D B Bradley, who lived in Siam from 1835 until his death in 1873. Of a total of 3,650 patients he treated over a one year period from May 1836 to April 1837, he recorded five cases of gonorrhoea and one hundred and thirty six cases of syphilis. ${ }^{5}$ These figures indicate that STDs were quite common in Bangkok at that time, and this situation is believed to have continued through the Fourth Reign and into the reign of King Rama V (1868-1910). ${ }^{6}$ However no further figures on the prevalence of STDs are apparently available until the early 20th century, after the establishment of the Western-style hospital system.

The figures available for the early 20th - century, during the reign of King Rama VI (1910-1925), indicate an alarming situation in regard to the prevalence of STDs. A report in the Bangkok Daily Mail newspaper of February 1914 gives a figure of $80 \%$ for people presenting at Sirirat Hospital (the city's major hospital at that time), and a similar figure for Wachira Hospital. ${ }^{7}$ Another source estimates that during this period $75 \%$ of adult males in Bangkok suffered from STDs. ${ }^{6}$ Among Wild Tiger soldiers stationed at the Ban Pong army camp during this period the prevalence was also estimated to be $80 \%{ }^{8}$

Despite the development of the Thai health and medical system, this situation appears to have remained unchanged into the late 1920s. In 1927 a contributor to the paper Sri Krung, writing under the name "Dr Phlong", cited information obtained from a public health doctor who estimated that ' 80 per cent of the population of Greater Bangkok were infected with the organisms that cause venereal disease'.?

By this time STDs clearly affected people at all levels of society. Bearing in mind the scarcity of sources and their bias towards the Thai elite, it appears that prior to the 19 th century STDs were largely a disease of the affluent. Thus in the mid-19th century the French missionary Bishop Pallegoix was still able to comment that "venereal disease is common among the rich", adding that it was a just punishment for their polygamy and debauchery. ${ }^{10}$ By the early 20th century, however, men from a variety of occupations ranging from rickshaw pullers to public servants were likely to be infected. ${ }^{7}$ There was concern, too, that STDs followed the trade routes into neighbouring regions such as Laos, ${ }^{11}$ although this no doubt worked both ways and it is likely that STDs also accompanied the Yunnanese traders along the routes from China into northern Thailand. The movement of people across these borders may also be an important contributing factor in regard to the high prevalence of STDs in northern Thailand today.

\section{Official responses}

Official responses to the problem of STDs were closely linked to those made to the problem of prostitution. The first government involvement came around 1897 when it was suggested that a tax farm, known as the Road
Maintenance Tax, be transferred to the Public Health Department of the Ministry of Municipal Affairs. It appears that this move was partly motivated by a concern for the prevention of venereal disease, and plans were discussed to use part of the revenue to improve hospitals, including the establishment of a hospital for prostitutes, although ultimately this did not eventuate. ${ }^{12}$

A Western medical doctor, $\mathrm{H}$ Campbell Highet, was involved in the subsequent drafting of the proposed Prostitution Law of 1898 carried out by the Public Health Department. At a meeting held to discuss the proposed law, Kromluang Therawong suggested that the name was not appropriate and asked that it be changed to the Law for the Prevention of Venereal Diseases. It was under this new name that the law was further discussed at meetings in February and March 1908 before being approved by King Chulalongkorn (Rama V) for enactment on 1 April 1908.

In his preamble to the Law for the Prevention of Venereal Diseases, Chulalongkorn justifies its introduction as follows: "some women are suffering from diseases which could be transmitted to the men who have relations with them. As there are no doctors to examine them and treat their diseases these are likely to keep spreading until they become a great danger to humankind". ${ }^{8}$

The law contained provisions for the compulsory registration of all prostitutes and premises used for prostitution. In addition to obeying a number of restrictions on the conduct of their profession, all prostitutes had to undergo a regular medical examination carried out by a government doctor. Any woman found to have a communicable disease was not to be allowed to work, and had to hand in her permit and seek medical attention. The permit was returned on presentation of a doctor's certificate. ${ }^{8}$ Registration figures for the year following introduction of the Law showed 2,500 prostitutes operating in 319 licensed brothels. ${ }^{12}$

It is worth noting at this point that the focus of these early measures to prevent STDs was placed squarely on female prostitutes. In fact one of the Thai words meaning "prostitute" is ying sanchon rok, literally "[venereally] diseased woman" ${ }^{13}$ Little or no concern is evident for the rehabilitation of, or provision of medical care for, the women, and no share of responsibility was directed towards their male clients. ${ }^{8}$ This pattern is one which has characterised official responses to STDs right up until the present day.

As it turned out, the Law for the Prevention of Venereal Diseases soon proved to be ineffective with prostitutes refusing to allow themselves to be examined. Some brothels were forced to close for a short time with a subsequent fall in government revenue derived from the brothels' sale of opium. The laxness in enforcement of the provisions of the Law for the Prevention of Venereal Diseases which followed the reopening of the brothels has been attributed to a concern for protection of this important source of rev- 
enue. ${ }^{8}$ The law continued to come under criticism for its ineffectiveness. ${ }^{7}$

It seems that little was done however. In 1922 a women's magazine, Nari Sapada, carried an article attacking the spread of venereal disease and proposing either the closure of brothels ("to the existence of which the powers that be, for the most part, close their eyes") or bringing them under close medical supervision. ${ }^{14}$ A short time later the Public Health Department (PHD, established in 1918) was reported as being convinced that the Law was "worthless from a public health point of view" as "it continues the now discredited principle of regulation and medical examination". According to the report, the Department was not prepared to undertake any extensive campaign for the control of STDs. ${ }^{15}$ These sentiments were further echoed a few years later by "Dr Phlong" in an article in the paper Sri Krung in 1927. He accused the government of only being interested in the suppression of prostitution, rather that the prevention of STDs. His response was that there should be greater medical supervision. ${ }^{9}$

In 1925 the Bang Rak Hospital (apparently formerly a clinic established by a Western doctor, Heywood Hays) came under the control of the PHD. Bang Rak Hospital had a communicable disease division which seems to have been responsible for the treatment of STDs $^{16}$ and from around 1927 there was talk of requiring the hospital to specialise solely in these diseases. ${ }^{9}$ Following a trip by Prince Sakol Voravarn to observe STDs in some forty four countries, a decision was apparently made in mid-192917 and the hospital opened towards the end of 1930 with the establishment there of the Control Unit to Reduce Venereal Diseases, under the Education Division of the Public Health Department. ${ }^{16}$ The charge for treatment was fixed at 1 baht. ${ }^{18}$ The PHD had by this time also commenced health education programmes, which were to eventually become available to venereal disease patients of the Bang Rak Hospital. ${ }^{19}$

The period from the 1930s to the $1980 \mathrm{~s}$ 1930-1939

During this period, the 1908 Law for the Prevention of Venereal Diseases remained in force, and prostitution continued under the registration system. There are no data available concerning STDs. By the late twenties it appears that registered prostitution was on the decline, owing perhaps to the general economic downturn of the time. Still, unlicensed brothels were common, with the police estimating some 300 sly prostitutes in Bangkok, while another informant to the League of Nations' Commission claimed as many as $2000 .{ }^{19}$ Police estimated that $30 \%$ of patrons of brothels were married men. ${ }^{19}$ There was a general concern that STDs were on the rise, and there were calls to ban places used for prostitution, which was said to be giving the country a "disgusting reputation". ${ }^{20}$ While Zimmerman claims that in the late 1920s prostitution was "not found among the [rural] Siamese", it is clear that Bangkok could not be so described. ${ }^{21}$

It is also clear that another reason for increased attention given to STDs and prostitution control derived from the interest of the League of Nations. ${ }^{22}$ Thailand had had problems with the League over the age of consent, which was 12 years, and the government had argued that it could not be raised. Indeed it was only in 1987 that the age of consent was raised to 15 years.

\section{9-1949}

There were some important organisational changes in the health services during this period. The Venereal Diseases Unit became a part of the Social Medicine Division of the PHD in 1938, but in 1942, the Division's name was changed to the Venereal Diseases Hospital after it came under the control of the Regional Hospitals Unit of the Medical Department. This change came about as a result of the PHD being included in the new Ministry of Public Health (MOPH). Subsequent reorganisations in 1945 and 1947 did little to change the fact that Bang Rak Hospital remained the centre for STD control. Later, however, and the date is not clear, similar control units were established in Lampang in the North and Nakorn Sawan in the Central Plains.

In 1938 a plan for the prevention and control of STDs was drawn up by the Division of Health Education, but it was never implemented. Prostitutes were apparently considered a problem, especially where licensing did not operate, and prostitution was said to be on the increase in the provinces. The plan had distinguished between Bangkok and other areas and between prevention and treatment. Prevention emphasised education, prostitute control, and new laws. ${ }^{23}$ Just prior to the outbreak of the Pacific War, this initiative was taken up by a private welfare group which was established to provide hygiene training for registered prostitutes, to be beneficial "to the women themselves as well as their clients...". This was said to have the support of the authorities, although the Ministry of Interior denied its support. ${ }^{24}$ This appeared to coincide with an attempt to change officially the organisation of prostitution.

The police recommended to the Ministry of Interior that registration of brothels and prostitutes be replaced by a system of medical control.25 An editorial in the Bangkok Chronicle noted that the police recommendation had been accepted by a Ministry of Interior committee examining prostitution. This was said to be in line with a resolution adopted at an International Conference on Health and Hygiene held in Java "a few years ago". The editor saw this as a progressive step both in terms of morals and hygiene. It was felt that the old [1908] law failed for lack of medical personnel and because the prostitutes concealed their true medical condition. However the editor also noted that underground prostitution might flourish if the licensing system was abolished. He urged 
strong measures against pimps and those preying on women and children and "stricter control over the spread of diseases and ... a progressive campaign of public enlightenment in the matter". ${ }^{26}$

No decision was taken, however, and registration continued. In 1942 a new law was drafted by an inter-ministerial Venereal Disease Prevention and Suppression Committee, but, again, was not enacted. The draft law would have suppressed all prostitution except licensed prostitution, and would have allowed a health officer who suspected someone of having an infection to compel that person to be treated at a medical centre. ${ }^{23}$ So, again, the 1908 law remained in force.

Following the Second World War it appears that there was an STD problem, perhaps fuelled by occupying troops. ${ }^{27}$ It may be, however, that STDs were, in part, being confused with yaws (treponematosis), which reached epidemic proportions during the war. ${ }^{28}$ Even so, the unavailability of drugs during the war saw STD incidence increase. ${ }^{28}$

\section{$1950-1965$}

In 1952 the PHD became the Health Department, and the Veneral Diseases Unit was expanded to become the Venereal and Treponematous Diseases Control Division. At this time it is reported that for the first time the government was receiving external assistance in this area. For example, assistance was received from the UN for the introduction of STD education amongst Thai students. Thailand also received $U N$ and US assistance for its venereal disease control programme. ${ }^{23}$ The one STD hospital had ten beds, and while generally charging for treatment, would waive this for poorer patients. ${ }^{28}$ In 1962 this Division was transferred to the Medical Science and Health Department in a Ministerial reorganisation.

Information on the incidence of STDs was inadequate, although in Bangkok the incidence was known to be 'fairly high'. In 1950, data from the three control units in Lampang, Bangkok and Nakorn Sawan suggested an incidence rate of 5-8 percent. ${ }^{28}$ This is confirmed in the summary of the Department's work in Table 1 .

The 1908 Law remained in force, but in 1954 yet another attempt to introduce a law to ban prostitution was made, and again lapsed. Instead, the Public Welfare Department was directed to regulate more closely the living and working conditions of prostitutes.

It appears that again there was a perceived relationship between the expansion of prostitution and venereal disease. For example, an

Table 1 Information on veneral diseases, 1951-6128

\begin{tabular}{lcc}
\hline Year & No. of STD patients treated & No. of treatment centres \\
\hline 1951 & 22,665 & 4 \\
1952 & 16,666 & 8 \\
1953 & 28,396 & 13 \\
1954 & 27,271 & 13 \\
$1955-1961$ & 505,607 & 14 \\
\hline
\end{tabular}

editorial in the Siam Rath Weekly Review warned the government against banning prostitution, calling instead for better medical supervision: "There is no denying that brothels are not only the breeding place for venereal diseases but also for all kinds of dread infectious diseases. "29 An academic report of the period argued that unlicensed prostitution was large, including "vast numbers" of streetwalkers, and that STDs in Bangkok corresponded to this increase in prostitution. ${ }^{28}$

Wendell Blanchard and his colleagues made the point tht prostitution "thrives as a lucrative investment for businessmen and some government officials". ${ }^{28}$ This was confirmed when the Hotels Association requested that police allow prostitutes to enter hotels "since the greater part of a hotel's income is derived from this source". Prostitutes would not be allowed to live in the hotels, but to enter with men. ${ }^{30}$ In 1957 it was estimated that there were 20,000 prostitutes in a population of 22 million, with half of these prostitutes being in Bangkok and Thonburi. ${ }^{23}$ Registration had clearly fallen by the wayside, with official figures showing only 103 registered brothels and 1,133 prositutes. ${ }^{23}$

In 1957 it was reported that periodic medical inspections were not being conducted, ${ }^{23}$ the rationale being that the prostitutes themselves sought treatment if they believed they were infected. One private clinic, serving some 500 registered prostitutes and about 1,000 unregistered, reported that positive STD findings had been reduced from $90 \%$ in 1937 to 25 percent in 1957, though rates outside Bangkok were believed to be higher. ${ }^{23} \mathrm{By}$ this time self-treatment was also available from shops selling antibiotics which would have further reduced clinical consultations. ${ }^{23}$

Fox noted that there was virtually no official effort to suppress prostitution, but in 1957 yet another draft law was proposed to replace the 1908 Act. $^{23}$ This draft was called the Prohibition of Prostitution Business Act, ${ }^{23}$ and it placed almost all emphasis on prostitution suppression and rehabilitation, with no mention of STDs. ${ }^{23}$ It seems that there was an official belief that the control of prostitution would greatly reduce STDs, but Fox, the UN Social Welfare Adviser, warned that suppression might only succeed in driving the trade underground. ${ }^{23}$ This draft was revised in 1960 , and was passed in that year, ${ }^{31}$ bringing to an end the long period of control through registration of brothels and prostitutes.

\section{6-1980}

This period coincides with an era of expansion in what was now illegal prostitution, as US military bases were built up in Thailand and as thousands of servicemen came on Rest and Recreation (R\&R) from Vietnam. Bangkok had long been regarded as a paradise for Western males interested in sex and relationships between Western men and Thai prostitutes, bar girls and boys, cabaret artists, and the like spawned a whole genre of literature. However, it was during the Vietnam war 
period that Thailand's international reputation as a sex haven was established. It was also during this period that Thailand promoted itself as a major tourist destination.

Ministerial arrangements appear to have continued much as before, although in 1974 a name change occurred to the Venereal Diseases Division within the Communicable Diseases Department of the MOPH. Interestingly, one general text of the period noted that the MOPH was "one of the bestrun government agencies". ${ }^{32}$

Henderson and others reported that by 1969-70 STDs, and especially syphilis, were still a major problem in urban areas: "Although prostitution is forbidden by law, the fifty-odd venereal disease clinics throughout the country report that about 5 percent of the population have contracted the disease". ${ }^{23}$ It was added that the real rate was probably much higher. This was in part because the rural incidence was unknown. While the literature often states that rural areas did not suffer STDs, there is never evidence to support this. In fact, data for 1973 (see table 2) suggest that STDs were quite common outside Bangkok.

Prostitution was also on the rise in this period. In 1969 it was officially reported that there were 2,417 brothels with 50,689 prostitutes in Thailand. Referring to statistics from the Venereal Diseases Division of the MOPH, it was estimated that this represented only about $34 \%$ of all prostitutes. It was also stated that in 1968-69, the number of prostitutes increased $20 \%$, from 151,244 to 182,495 . However, other reports of the period (for example the World Bank) estimated up to 300,000 prostitutes. ${ }^{33}$

Officially, there was no concerted effort to suppress the industry, as there had occasionally been in previous eras. Indeed, as Harris reports, the opposite was often true. $\mathrm{He}$ records an interview with General Prapas Charusathiarana, arguably Thailand's most powerful man and Minister of the Interior in the sixties, who wanted a larger sexual service industry, claiming it was good for the economy, attracting tourists. ${ }^{34}$

It has been argued that high-profile foreign tourist enclaves like Patpong resulted from the influx of American soldiers on $R \& R$ from Vietnam (or as Dawson ${ }^{35}$ refers to it, I\&I Intoxication and Intercourse). ${ }^{36} \mathrm{~A}$ contrary view holds that the soldiers had little to do with Patpong, although the war-bloated Thai economy did much for the street's development as a centre of the expatriate sex industry. ${ }^{35}$ Indeed, while American servicemen had pulled out by 1976, tourism was growing,

Table 2 Incidence of gonorrhoea and syphilis in selected provinces, $1973 .^{32}$

\begin{tabular}{|c|c|c|c|c|}
\hline \multirow[b]{2}{*}{ Province } & \multicolumn{2}{|c|}{ Gonorrhoea } & \multicolumn{2}{|c|}{ Syphilis } \\
\hline & No. & $\%$ & No. & $\%$ \\
\hline $\begin{array}{l}\text { Nakorn Ratchasima } \\
\text { Bangkok } \\
\text { Cholburi } \\
\text { Chiangmai } \\
\text { Songkhla } \\
\text { Totals }\end{array}$ & $\begin{array}{r}46,310 \\
41,310 \\
28,524 \\
24,088 \\
13,979 \\
154,979\end{array}$ & $\begin{array}{r}30 \\
27 \\
18 \\
16 \\
9 \\
100\end{array}$ & $\begin{array}{r}849 \\
2,925 \\
1,462 \\
749 \\
871 \\
6,856\end{array}$ & $\begin{array}{r}12 \\
43 \\
21 \\
11 \\
13 \\
100\end{array}$ \\
\hline
\end{tabular}

Table 3 Incidence rate of STDs (per 1000 persons) ${ }^{37}$

\begin{tabular}{llcc}
\hline Age & $1967-71$ & $1972-76$ & $1977-80$ \\
\hline 15 years and over & $5 \cdot 77$ & $10 \cdot 17$ & $12 \cdot 18$ \\
All ages & $3 \cdot 29$ & $6 \cdot 11$ & 6.95 \\
\hline
\end{tabular}

Table 4 Incidence rate of gonorrhoea, (per 100,000 persons) ${ }^{37}$

\begin{tabular}{llll}
\hline Age & $1967-71$ & $1972-76$ & $1977-80$ \\
\hline 15 years and over & $372 \cdot 53$ & $586 \cdot 79$ & $620 \cdot 01$ \\
All ages & $212 \cdot 34$ & $334 \cdot 43$ & $353 \cdot 40$ \\
\hline
\end{tabular}

and the sharp rise in prostitution was maintained.

Data on STD rates of infection from 1967 to 1980 for the 5 notifiable diseases specified by the MOPH (gonorrhoea, syphilis, chancroid, lymphogranuloma venereum and granuloma inguinale) are available, and are summarised in tables 3 and 4 .

Niwat notes that the increase for the 15-25 year age group was among the highest in the world. His explanation for this rate increase notes various factors including: the behavioural basis of STDs, the changing sexual behaviour of the youth, and a rapidly changing society. ${ }^{37}$ Niwat also identifies the expansion of the sex industry, male homosexual behaviour, and birth control, and the lack of sexual knowledge as factors. ${ }^{37}$

The official promotion of the technically illegal sex industry continued, with 1980 being declared the "Year of Tourism". One aspect of this was the highly publicised statement by high-profile deputy premier, banker and businessman, Boonchu Rojanasathien, exhorting provincial governors to promote sex tourism in order to benefit the economy. ${ }^{38}$

In its 9 January 1980 issue, Tawan Mai magazine estimated, using police statistics, that more than 400,000 Thai women were involved in the sex industry (see table 5) ${ }^{39}$

\section{The AIDS era}

Prior to the arrival of HIV/AIDS in Thailand, other STDs continued to be a major problem. For example, the Director of the STDs Department at Bang Rak Hospital claimed that STDs were spreading at an alarming rate in the mid-1980s. He estimated that in a population of 50 million, there were 3 million cases, ${ }^{36}$ which agrees with Thitsa's $70 \%$ figure for the proportion of Bangkok's prostitute population infected with STDs. ${ }^{40}$ Sukanya reported a study of 1,000 prostitutes conducted in 1980, which showed $41 \%$ had some form of STDs. ${ }^{31}$ In addition, a study by

Table 5 Estimates of size of sex industry in Thailand, $1980^{39}$

\begin{tabular}{lrc}
\hline Establishment & No. & No. of women workers \\
\hline Bars and nightclubs & 4,314 & 181,615 \\
Brothels & 9,367 & 171,973 \\
Massage parlours & 1,589 & 32,162 \\
Hotels with prostitutes & 2,139 & 25,719 \\
Other places with sexual & & \\
services & 2,562 & 14,531 \\
Hairdressers and massage & 102 & 908 \\
Totals & 20,073 & 426,908 \\
Only 729 of these establishments were reported to be in \\
Bangkok.
\end{tabular}


the Institute of Population Studies at Chulalongkorn University indicated that $40 \%$ of teenagers had had an STD by the time they were 17 years. But it was HIV/AIDS which became the focus of attention, becoming a notifiable disease in May 1985.41

Three years elapsed between the first case of AIDS - described in the US in 1981 and the first recorded case in Thailand which was diagnosed in Bangkok in 1984. Three years later, a fairly definite picture was emerging of the profile of the then very slowly increasing group of sufferers: by 1987, there had been only eight cases of AIDS or ARC (AIDS Related Complex) Disease diagnosed and a further $112 \mathrm{HIV}$ positive cases identified. The major distinguishing characteristics of this group - who provided what has been called "the first epidemic" of AIDS in Thailand - were that they were largely male, homosexual and almost half were foreigners.

Within a few months, however, the situation was changed dramatically to involve Thailand's estimated 100,000 intravenous drug-using community, the so-called "second epidemic". This group was still overwhelmingly male but largely heterosexual and it was clear that the disease could now pass easily via heterosexual contact into a second, also highly susceptible, but even larger pool female sex workers - and from these eventually into the still larger population of mainstream Thais.

While much of the publicity around Thailand's sex industry has focused on the rich foreigner, there is clear evidence that the garish and highly visible red-light districts of Patpong and Pattaya are but the tips of the iceberg. There is also an enormous and widespread, if less publicised, use of female prostitutes by Thai men from all classes, ages and regions, in comparison with which that part of the sex industry catering for foreigners pales considerably in significance.

In order to examine the date on the progress of the disease into the sex industry it may be instructive to follow one particular group of prostitutes from the Northern Region who have been successively monitored over the key period of the late eighties by the Ministry of Public Health.

These data from Chiang Rai Province reveal the following pattern: in August 1987, none was infected by HIV; by October 1988, the survey indicated the rate had risen almost 1\%; a year later, in November 1989 the figure had jumped to $37 \%$, while by June 1990 it had reached $54 \%$. Even allowing for some errors in sampling this population and perhaps its particular susceptibility, it was clear that the disease was sweeping through a new and at-risk population of female sex workers.

If the explanatory mechanism proffered here is correct, then it would be predicted that there will be a steady, if not spectacular rise in the positivity rate in the wider population of low-risk Thai males at the end of the decade. The disease would then be expected to spread into the mainstream female Thai population.
While there had been no large scale survey of the prevalence of HIV in the general community until very recently, it was known that positivity rates in those not in high-risk categories were low up to towards the end of the decade. In 1990, a national survey was conducted to examine this issue, concentrating on young men representing a cross-section of the Thai urban and rural population: of 32,000 males surveyed, and aged between 20 and 22 years, $1.7 \%$ were positive. When extrapolated to the whole population this would indicate the presence of a very large infected and asymptomatic group. Moreover the study also showed that infection was far higher in certain areas such as the North, where rates among prostitutes were so high: in Chiang Rai for instance, $11.5 \%$ of the young men were infected, with rates rising to $15 \%$ in some districts. High rates of infection have also been found amongst hill tribe people, Burmese and Yunnanese female prostitutes, and other groups of people associated with these border areas. ${ }^{42} 43$ Clearly these groups could act as a reservoir of infection for the whole country.

As far as we can tell there is no equivalent study so far on the rates of infection in the low-risk Thai female population: however, it is quite clear on the basis of the above data that the disease is spreading rapidly into this group - and so into their offspring. At the end of 1990, Mechai Viravaidya, the Secretary General of the Population and Community Development Association and the person who has done most to bring the issue of AIDS to the attention of the public, estimated that at that time 400,000 Thais were infected, though he claimed in a trenchant letter to The Nation that the number may be twice that. ${ }^{44}$

\section{Responses to the AIDS epidemic}

In brief the public response can be characterised as having three phases: first, a phase of denial, which lasted from the beginning of the outbreak in 1984 to the end of the decade and corresponded with what we have called the first two and the beginning of the third epidemic waves; second, a phase of more active monitoring and public education and the beginning of Governmental legislation (the aborted Anti-AIDS Bill of the Chatichai Government); this lasted from the early $90 \mathrm{~s}$ to the present; finally, at the time of writing (September 1992), there appear to be signs of an emerging third phase, with the commitment of major resources to programmes which not only monitor the disease and provide health education and counselling, but increase community support for sufferers and facilitate the beginnings of multi-sectoral development programmes.

As early as 1985, the Sexually-Transmitted Diseases Division of the Communicable Diseases Control Department had educational material available, and was providing it to prostitutes. Unfortunately this material reproduced some erroneous information. For example, it was stated that the virus was 
found in blood, semen and saliva, and that homosexual sex with foreign partners was a special risk. Advice on how to avoid AIDS was to abstain from sex with homosexuals, infected persons, people close to infected persons, foreigners, and injecting drug users. In addition, the pamphlet urged that kissing on the mouth be avoided if a person was suspected of being infected, that blood from infected persons be avoided, as well as the shared use of needles. ${ }^{45}$ Initially it was left to non-government organisations to provide more useful information. ${ }^{46}$

The phase of denial was characterised by a widespread belief that the condition was not only very rare but a foreign import and one extraneous to Thai society; this was demonstrated sharply by the attempt in 1989 by Bangkok's oldest and most prestigious university to screen only their foreign staff. This brought a vigorous response from Mechai who was clear as to its wider implications for the whole AIDS programme: as reported in The Nation he said "I'm sure the Thai professors are more likely to get AIDS than the farang (foreigners)". ${ }^{47}$

Contributing further to the ease with which the problem could be ignored was the focus of the earlier waves on another group of society's marginalised people - homosexuals and drug addicts. Nothing better could be said here to exemplify the "phase of denial" than to note that the Thai Prime Minister was quoted as saying that AIDS was not a problem in Thailand. ${ }^{48}$

Coupled with a denial of the problem were hasty and severe measures taken against those found to have the disease. A good example was the response following the official announcement that $40 \%$ of prostitutes in the Chiangmai area had tested positive for HIV in July 1989. High-level MOPH officials immediately called for the infected prostitutes to be arrested. An editorial in The Nation lamented: 'Such a 'strong-man' approach to the spreading pandemic is politically attractive because it gives officials the appearance of taking action. It also satisfies the sensitive moralities of those who still cling to the illusion that Aids affects only 'bad' or 'sexually promiscuous' people, who should be 'punished' for their depraved lifestyles."

The Nation argued that such measures were doomed to failure, were reactionary, and could only delay really effective strategies including a vigorous education campaign. ${ }^{49}$

Within the Ministry, there was a strong move for the development of better, and especially educational, policies, in opposition to those advocated by the leadership of the Ministry. ${ }^{50}$ Nevertheless, even those officials who had a role to play in education and had good information regarding the disease were reluctant to alter their personal behaviour. One of the authors reports a social meeting in January 1992 with a senior MOPH official from Bangkok and two regional heads of MOPH centres, where AIDS was discussed. Within a short time three young women were brought for the selection and use of the senior official.

However, in defence of the ostriches, it must be emphasised that owing to the unique natural history of the condition-with its relatively long latent period-the very rapid, but hidden, spread of the disease in Thai conditions was a difficult concept to grasp. Even now, the MOPH reports that as at September 1992, only 895 full-blown cases of AIDS have been reported and of these 491 are still alive.

While the MOPH has been criticised for its sluggish response to the epidemic one of the authors remembers that a senior MOPH administrator working in the area told him privately in 1988 that he was in despair at the lack of interest in and support for the AIDS initiative from the politicians. Further evidence for such lack of political support was provided in The Far Eastern Economic Review of 21 June 1990. There appear to have been few changes to the structure of the Ministry related to STDs in this period, with the significant exception of the establishment of the AIDS Centre within the Department of Communicable Diseases in 1989. The Health Education Division continued to flounder and to work with a limited budget. However, it is clear that there was considerable dissension concerning the STD control policies adopted by the MOPH, especially with respect to HIV/AIDS.

Not only ignorance and denial explain this lack of support for the health bureaucracy: it is clear that powerful entrenched interests in the tourism and related sex industries were and are terrified by the economic implications of the epidemic for their businesses. From time to time these groups went public and denounced the "hysteria" of the campaign against AIDS, targetting the hip-pocket nerve by claiming the campaign was having a serious effect on the inflow of foreign tourists and the Thai economy. ${ }^{51}$

Thus a combination of factors, some of these related to the less salubrious aspects of Thailand's rapid economic growth, worked together to hinder an effective response by Government to the threat of AIDS. Eventually however the Government had to respond, not the least because of the very considerable pressure exerted by WHO and foreign Governments.

By 1990 the Thai government had a budget of US\$4 million for AIDS education. The MOPH was moving towards cooperation with brothel owners, mounting a condom campaign. ${ }^{52}$ Even so, the MOPH was still pushing for draconian control legislation, and promoted this at an international AIDS congress in Bangkok. This congress had been boycotted by many international delegates and WHO because of Thailand's existing discriminatory legislation. This caused considerable embarrassment as the congress was organised by the King's youngest daughter. Former prime minister and Privy Council member, Professor Thanin Kraivixian, in a speech to the congress, supported strict control of "irresponsible" people such as prosti- 
tutes, homosexuals, drug addicts and prisoners. He was supported by high-level MOPH officials. All other speakers were reported to be highly critical of the draft legislation..$^{53}$ Considerable opposition to its more authoritarian measures of arrest and detention was led by Mechai and other non-government organisation leaders such as Jon Ungphakorn, and this and the tumultuous events of the military take-over eventually led to its being shelved.

Interestingly, soon after the extent of the epidemic had become apparent, Thailand's gay community had quickly moved into education, especially in gay bars, and this appears to have been quite successful. ${ }^{54}$ In Bangkok, the HIV infection rate amongst homosexual men was only $0.4 \%$ in $1990 . .^{55}$ It was perhaps the success of these programmes and the high-profile criticism and educational programmes promoted by Mechai and his Population and Community Development Association $^{56}$ which were eventually to turn the government's programmes around.

By 1991, however, more realistic AIDS policies were being implemented. The impetus for this came largely from strong international pressure, staffing changes within the $\mathrm{MOPH}$, and increased domestic pressure, especially from non-government organisations. There were signs that the phases of denial and then paralysis had begun to be replaced by far more positive, communitybased initiatives, many of them highly innovative. Not surprisingly, this coincided with the tenure of Mechai as a minister in the interim Anand Panyarachun government from February 1991 to March 1992. Unexpectedly, prostitution was decriminalised.

\section{AIDS-the present situation}

Table 6 shows the current situation as reported by the MOPH in September 1992. In summary, there were known to be 2043 persons who either had AIDS or had AIDSrelated illnesses, of whom 85 percent were male. This is in contrast to the data for September 1991, which recorded a total of 607 cases of AIDS and ARC. ${ }^{57}$

In striking counterpoint to this is the evi- dence from community prevalence surveys and other data which suggests that there may be a further 400000 or even a million. Thais in the early and unrecorded stages of infection. The above outline has shown how this situation has arisen and indicated that the next few years will increasingly reveal the full impact of the epidemic: as the clinical disease emerges, huge numbers of Thai men and women, many of whom will be in their most productive years, will begin to drop from society and then to require increasing levels of medical and social support. The human and social consequences in terms of orphans, and the disruption and weakening of key local and national community institutionsprocesses already underway in Africa-will accelerate and multiply the economic costs.

It is clear that Thailand has a long and arduous road ahead if anything is to be done to ameliorate the effects of the AIDS epidemic. In our view, there is room for some cautious optimism: the last two years have witnessed the appointment of the Prime Minister as chair of the National AIDS Committee and a Minister (Mechai) to oversee the AIDS programmes, as well as the allocation of substantial funds to the MOPH. Equally important are a number of community-based initiatives which are aiming to tackle, or at least confront, the unpalatable connections between the epidemic and some entrenched aspects of Thai society. As Mechai points out, failure will be very costly.

The other STDs-the current position

The latest reports indicate that overall STDs, with of course the exception of AIDS, have very recently shown a significant decline. MOPH data show the changing pattern of reported STDs: rates for all five diseases classified as STDs-gonorrhoea, non-gonococcal urethritis/vaginitis, chancroid, lymphogranuloma venereum, and syphilis-have begun falling from a high in the period around 1987 and have maintained consistent falls in the last 3 years.

While the explanation for this is not entirely clear, there have been increasingly systematic attempts regularly to monitor and educate sex workers and to treat when infec-

Table 6 Distribution of AIDS and ARC by sex and risk behaviour (data as of September 15, 1992) ${ }^{57}$

\begin{tabular}{|c|c|c|c|c|c|c|}
\hline \multirow[b]{2}{*}{ Risk behaviour/Sex } & \multicolumn{2}{|c|}{$A I D S$} & \multicolumn{2}{|l|}{$A R C$} & \multicolumn{2}{|l|}{ Total } \\
\hline & No. & $\%$ & No. & $\%$ & No. & $\%$ \\
\hline 1. Sex-related & 683 & $76 \cdot 3$ & 873 & $76 \cdot 0$ & 1,556 & $76 \cdot 2$ \\
\hline Homosexual male & 26 & $2 \cdot 9$ & 23 & $2 \cdot 0$ & 49 & $2 \cdot 4$ \\
\hline Bisexual male & 13 & 1.5 & 10 & 0.9 & 23 & $1 \cdot 1$ \\
\hline Heterosexual male & 581 & $64 \cdot 9$ & 693 & $60 \cdot 4$ & 1,274 & $62 \cdot 4$ \\
\hline Heterosexual female & 63 & $7 \cdot 0$ & 147 & $12 \cdot 8$ & 210 & $10 \cdot 3$ \\
\hline 2. IVDU & 82 & $9 \cdot 2$ & 186 & $16 \cdot 2$ & 268 & $13 \cdot 1$ \\
\hline Male & 80 & $8 . \overline{9}$ & 179 & $15 \cdot 6$ & 259 & $12 \cdot 7$ \\
\hline Female & 2 & $0 \cdot 2$ & 7 & 0.6 & 9 & 0.4 \\
\hline 3. Blood transfusion & $\overline{9}$ & $1 \cdot 0$ & 6 & 0.5 & 15 & 0.7 \\
\hline Male & 8 & 0.9 & 4 & $0 \cdot 3$ & 12 & 0.6 \\
\hline Female & 1 & $0 \cdot 1$ & 2 & $0 \cdot 2$ & 3 & $0 \cdot 1$ \\
\hline 4. Vertical transmission & 111 & $12 \cdot 4$ & 46 & $4 \cdot 0$ & 157 & $7 \cdot 7$ \\
\hline Male & 60 & $6 \cdot 7$ & 24 & $2 \cdot 1$ & 84 & $4 \cdot 1$ \\
\hline Female & 51 & $5 \cdot 7$ & 22 & 1.9 & 73 & 3.6 \\
\hline 5. Unidentified & 10 & $1 \cdot 1$ & 37 & $3 \cdot 2$ & 47 & $2 \cdot 3$ \\
\hline Male & 10 & $1 \cdot 1$ & 30 & 2.6 & 40 & $2 \cdot 0$ \\
\hline Female & 0 & 0.0 & 7 & 0.6 & 7 & 0.3 \\
\hline Total & 895 & 100 & 1,148 & 100 & 2,043 & 100 \\
\hline Alive and in country & 491 & $54 \cdot 9$ & 997. & $86 \cdot 8$ & 1,488 & $72 \cdot 8$ \\
\hline
\end{tabular}


tion is found. Moreover, despite the emergence of some resistant strains of infecting organisms, the much improved and now widely dispersed system of health services, and a regular supply of antibiotics, must have brought appropriate and effective care to many more of the population.

This promising picture has several implications for the response to AIDS. For a start, the data show that those with other STDs are at far greater risk of AIDS, suggesting the possibility that the STD programme, now in place, is in a good position to pick up, monitor and treat those with AIDS entering the system. Further the current STD health education programmes can be expanded to incorporate the new disease. In brief, the successes of the fight against the old scourges can help the programme required to combat the new.

\section{Conclusion}

A striking feature to emerge from this brief look at the history of STDs in Thailand is the close similarities between the present situation in regard to HIV/AIDS and that for the other STDs in earlier periods. In both cases these diseases were epidemic, and both then and now there was no cure, only measures to ease the suffering of those afflicted.

In this first attempt to look at the subject we have considered a number of social, economic and political factors which appear to have been responsible for the high prevalence of STDs in Thailand. The widespread use of prostitutes by men in Thai society is one of the most important of these. Another important contributing factor has been the links between government, business interests and sex. Throughout the period covered in this study the government has earned revenue, either directly or indirectly, from prostitution, and this association has constrained any serious measures undertaken to control the sex industry, and STDs.

In addition to these factors, there is the fact that those at greatest risk have lacked political power. The history of STDs in Thailand, at least until very recently, has been characterised by an accent on unsympathetic and often harsh treatment of their victims, and the direction of blame, as well as measures to control the diseases, towards women, particularly prostitutes. These groups have had little opportunity to have a say in the provision of services or other measures which would improve their position. Thus, in the past, as now, very little has been done either to provide for treatment and rehabilitation of sufferers or to address the fundamental social and economic circumstances which continue to encourage women and men to place their lives at risk.

There are certain other features of Thai culture and society which have not been considered in the context of the present paper. These include the custom of polygamy, and the modern practice of keeping of minor wives (mia not), as well as the extent to which the Buddhist religion has helped promote a relaxed attitude towards male sexual activity. In future research the significance, or otherwise, of these factors would have to be considered.

The authors gratefully acknowledge the support of the Politics Programme, Murdoch University, and the National Thai Studies Centre and the Anthropology Department (RSPacS), the Australian National University. The assistance of Ingrid Wijeyewardene in translating some difficult material, and the help of Matthew Copeland, Vanawipha Pasandhanatorn and Nitaya Vajanapoom in obtaining source materials are also greatly appreciated.

1 La Loubère S de. A New Historical Relation of the Kingdom of Siam. London: Oxford University Press, 1969.

Prachum Phongsawadan (Historical Texts) vol 39. Bangkok: Khurusapha, 1961 (in Thai).

3 Rongrian phaet phaenboran Wat Phrachetuphon (The Wat Phrachetuphon School of Traditional Medicine) ed and pub. Tamra ya silacharu'k nai Wat Phrachetuphon Wimonmangkhalaram (Traditional Medical Inscriptions of Wat phrachetuphon). Bangkok: 1962 (in Thai).

4 Samakhom rongrian phaetsat phaen boran Wat Phrachetuphon (The Wat Pho Traditional Medical College Association) ed. and pub. Phactsat songkhro (Texts on Medicine) 3 vols. Bangkok: 1961-76 (in Thai).

5 The Siamese Repository 5. Canton: 1837.

6 Thepphachu Thapthong. Ying khom khiaw ('Green Light Tepphachu Thapthong. Ying khom khiaw ('Green

7 Daily Mail. Bangkok, 13 February, 1914.

8 Dararat Mettarikanon. Prostitution and Thai Government Policy BE 2411-2503 (1868-1960). MA Thesis. Bangkok: Chulalongkorn University, 1983 (in Thai)

9 Sri Krung. Bangkok, 19 July, 1927 (in Thai).

10 Pallegoix J. Description du Royaume Thai ou Siam 1. Paris: Mission de Siam, 1854 (in French).

11 Spire C. Les Laotiens: coutumes, hygiene, pratiques médicales. Paris: A. Challamel, 1907 (in French).

12 Dararat Mettarikanon. Prostitution Law: the First Registration in Thailand. Silapawatthanatham (Arts and Registration in Thailand. Silapa
Culture) 5 (5), 1984 (in Thai).

13 Ratchabanthitsathan (Royal Institute). Photchananukrom chabap ratchabanditsathan P.S. 2525 (Royal Institute Dictionary). Bangkok: Akson Charoenthat, 1982 (in Thai)

14 Bangkok Times Weekly Review. 20 November, 1992.

15 Bangkok Times Weekhy Review. 4 December, 1922.

16 Information supplied by Sexually Transmitted Diseases Division, Department of Communicable Diseases. Bangkok: Ministry of Public Health, 1992.

17 Bangkok Times. 2 March 1929.

18 Bangkok Times Weekly Reviev. 24 November, 1930.

19 League of Nations Commission of Enquiry into Traffic in Women and Children in the East. Report to the Council. Geneva: League of Nations, 1932.

20 Bangkok Times. 2 March 1929.

21 Zimmerman C. Siam Rural Economic Survey 1930-31. Bangkok: The Bangkok Times Press. 1931.

22 Bangkok Times Weekly Review. 26 September, 1921.

23 Fox M.G. Problem of Prostitution in Thailand. Bangkok: Department of Public Welfare, Social Service in Thailand, Ministry of Interior, 1960.

24 Bangkok Chronicle. 14 November and 5 December 1939.

25 Bangkok Chronicle. 11 December 1939.

26 Bangkok Chronicle. 10 October 1940.

27 van Praagh D. Alone on the Sharp Edge: The Story of M.R. Seni Pramoj and Thailand's Struggle for Democracy. Beni Pramoj and Thailand

28 Blanchard $W$ et. al. Thailand: Its People, Its Society, Its Culture. New Haven: Human Relations Area Files, 1958.

29 Siam Rath Weekly Review. 27 May 1954

30 Siam Rath Weekly Review. 28 April 1955.

31 Sukanya Hantrakul. Prostitution in Thailand. Paper for the Women in Asia Workshop, Monash University, 22-24 July 1983.

32 Henderson J.W et al. Area Handbook for Thailand. Washington D.C.: Department of the Army, 1971.

33 Nation. Bangkok, 7 March 1989.

34 Harris A. Bangkok After Dark. New York: MacFadden Books, 1968 .

35 Dawson A. Patpong-Bangkok's Big Little Street. Bangkok: n.p., 1988.

36 Marchand D. Paying the Price of Prostitution: Gonnorrhea in Thailand. IDRC Reports 16 (2), 1987.

37 Niwat Phonnikon. Sexually Transmitted Diseases: Consequences for Society and its People. In Thanawadi Thachin and Phensiri Trakunsatchawat eds. Banha kan kha ying lae yutthisat kan kae banha (Problems Concerning the Trade in Women and Strategies for Solving the Problem). Bangkok: Chulalongkorn University Social 
Research Institute, 1984, 215-233 (in Thai)

38 Matichon (newspaper). 18 October 1980 (in Thai)

39 Tawan Mai (magazine) 9 January 1980 (in Thai).

40 Khin Thitsa. Providence and Prostitution: Image and Reality for Women in Buddhist Thailand. London: Change

41 Ministerial Notification No. 2. MOPH, 1 May 1985 (in Thai).

42 Nation. 7 March 1990

43 Sayam Rat Weekly Review. 25-31 August 1991 (in Thai)

44 Nation. 25 October 1990.

45 MOPH. The AIDS Disease. 1985 (in Thai).
46 Nation. 27 August 1987.

47 Nation. 24 August 1989.

48 Far Eastern Economic Review. 2 November 1989.

49 Nation. 11 July 1989.

50 Interviews MOPH. May 1990.

51 Nation. 21 August 1989.

52 Bangkok Post. 4 December 1990.

53 Nation. 21 December 1990

54 Nation. 25 April 1988.

55 Far Eastern Economic Review. 21 June 1990

56 Bangkok Post Weekly Review. 10 September 1989

57 Division of Epidemiology, MOPH. 